\title{
ОБРАЩЕНИЯ КАК СПОСОБ ВЫРАЖЕНИЯ ЭМОЦИЙ (НА МАТЕРИАЛЕ РУССКОГО, БЕЛОРУССКОГО И СЛОВАЦКОГО ЯЗЫКОВ)
}

\author{
APPEALS AS A WAY OF EXPRESSING EMOTIONS (ON THE MATERIAL \\ OF RUSSIAN, BELARUSIAN AND SLOVAK LANGUAGE)
}

\author{
ЕЛЕНА КАЛЕЧИЦ
}

AвSTRACт. Emotions put their imprint on all language levels and, most likely, are manifested in almost all appeals. The paper analyzes the appeals, synonymous with the word "grandmother", which perform pragmatic and expressive functions. On this basis, we call them emotives and emotives-regulators. Some nuances of their use in Russian, Belarusian and Slovak are described. The positive national and international emotional meaning of the appeals under consideration is underlined.

Keywords: appeals, basic emotions, regulators, emotional meaning, communicativepragmatic and cognitive-pragmatic approaches

Елена Калечиц, Университет имени Константина Философа в Нитре, Нитра Словакия, akalechyts@ukf.sk

ORCID ID: 0000-0002-5738-7168

Общаясь друг с другом, мы, как правило, обмениваемся своими эмоциями и в некоторой степени воздействуем на слушателя или собеседника с помощью языковых средств, отражающих наше внутреннее состояние и преследуемые цели. Причём, по мнению Натальи Орловой, именно эмоции служат стимулом к началу общения или к его завершению [Орлова 2009]. А согласно Людмиле Кожуховой, „обращение, особенно в начальной позиции, предваряет сообщение, ....задаёт тон всему процессу коммуникации" [Кожухова 2007: 83]. Мы также придерживаемся предположения, что эмоции отражаются в языке, и, скорее всего, на всех его уровнях.

Как известно, основные эмоции универсальны и хорошо понятны носителям разных культур даже без глубоких знаний чужого языка, так как эмоции выражаются не только вербально, интонационно, но и безошибочно распознаются по мимике говорящего, его жестам. К основным, базовым эмоциям, описанным Кэрролом Эллисом Изардом в работе Психология эмоций, относятся интерес, радость, удивление, печаль, гнев, 
отвращение, презрение и страх [Изард 2007: 49]. Этот же исследователь утверждает, что несколько обобщённая, традиционная классификация эмоций также является правильной: „Большинство учёных, как и обычные люди, неспециалисты, делят эмоции на положительные и отрицательные, на негативные и позитивные" [Изард 2007: 26]. Названное разделение эмоций, вероятнее всего, хорошо подойдёт и для нашей работы, поскольку считается достаточно простым, понятным и, самое главное, употребительным в учебном процессе в любой возрастной аудитории.

Изучение отражения эмоций в различных языках и культурах является актуальной и до сих пор мало изученной проблемой. О необходимости её освещения и дальнейшей разработки не только в лингвистике, но и других, смежных с ней дисциплинах подчёркивает Виктор Иванович Шаховский:

...эмоции являются таксоном культуры, и ...их вербализация в различных языковых культурах не всегда совпадает по форме, объёму и качеству эмотивных смыслов... Эмоция является ядром языковой личности, равно как рефлексия ядром его сознания, поэтому проблема „Человек в языке”, а следовательно, и проблема „Эмоции человека в языке” - это не только лингвистическая проблема. Это и дидактическая проблема, которая требует пересмотра традиционных методов обучения родному и неродному языку и переходу к новым направлениям в методике (коммуникативному, социосемиотическому, когнитивному) [Шаховский 2008: 292; 48-49].

Проанализировав степень изучения заявленной для обсуждения темы в научной, преимущественно русской, белорусской и словацкой лингвистической и методической литературе, мы пришли к выводу, что русско-белорусско-словацкие обращения с точки зрения отображения в них эмоций учёными ещё не рассматривались и не описывались.

О том, что при эффективном изучении иностранного языка огромную, даже доминирующую роль играет мотивация, всем преподавателям хорошо известно. И это положение не случайно, так как психологи утверждают, что именно эмоции образуют первичную мотивационную систему человека, они оказывают воздействие на его восприятие, мышление и поведение. Ср.:

Научение через переживание (как в личностном, так и в социальном плане) не менее, а быть может, и более важно, чем накопление информации... человек лучше усваивает тот материал, который соответствует его настроению [Изард 2007: 13-14].

Эмоции интереса и радости способствуют творческой и созидательной деятельности, играют большую роль в формировании и развитии навыка [Изард 2007: 50, 66, 99, 104]. Следуя данным замечаниям психоло- 
гов, необходимо на занятиях не только создавать положительную в эмоциональном плане атмосферу, но и обучать студентов на таком языковом материале, который был бы им интересен и полезен в каждодневной коммуникации, вызывал различные эмоции. По мнению учёных, „средства эмотивности должны вводиться и изучаться через систему упражнений одновременно со всеми другими средствами выражения" [Шаховский 2008: 50].

Так, в нашей работе эмотивами, или эмотивными словами, мы будем называть лексемы с коннотативным компонентом - экспрессивноэмоционально-оценочными семами. И в практике преподавания иностранных языков, на наш взгляд, лучше всего их рассматривать вместе с нейтральными синонимами, поскольку при сравнительном и сопоставительном рассмотрении таких лексических единиц экспрессивные семы будут более заметны обучающимся. Обращения, выраженные словами, как и любые полнозначные лексические средства, во-первых, носят номинативный характер, то есть называют адресата речи, а также выполняют дополнительные функции; вслед за иными лингвистами, мы их считаем полифункциональными. В языкознании данный подход называется коммуникативно-прагматическим. Последователи этой позиции считают, что обращение может выполнять номинативную, контактную (фатическую), вокативную (аппелятивную, или побудительную), этикетную, эмоциональную и оценочно-характеризующую функции [см. Жукова 2015: 49]. Кроме номинативной, фатической, вокативной и этикетной функций, по мнению Людмилы Гущиной и Людмилы Кожуховой, а также некоторых других лингвистов, обращения несут дейктическую функцию, указывают на адресата речи, и прагматическую управляют собеседником, воздействуют на него [Гущина 2006: 8-9; Кожухова 2007: 82]. Эмоциональную и оценочно-характеризующую функции, вслед за иными языковедами [см. Котовская 2011], мы предлагаем называть эмотивной функцией, так как эмоции и чувства практически всегда сопровождаются оценкой. Согласно Наталье Орловой,

эмоциональность представляет собой инстинктивное, бессознательное, незапланированное проявление эмоций, в то время как эмотивность - сознательная, запланированная демонстрация эмоций - является её лингвистическим выражением [Орлова 2009].

И это лингвистическое выражение эмоций, вероятно, проявляется практически во всех обращениях, даже тех, что, как правило, выполняют этикетную функцию.

Обычно любая коммуникация начинается с приветствия и обращения и, естественно, их выбор зависит от различных факторов: ситуации 
общения, возраста собеседников, их уровня образования, профессии, пола и т.д. По обращению мы можем определить, в каких отношениях находятся между собой коммуниканты. Обращаясь к собеседнику, мы выражаем своё отношение к нему, влияем на тон и ход беседы. Воздействуя на слушателя, мы выражаем свои эмоции, даём оценку событиям, ситуациям, другим людям и т.п., а также, безусловно, тому, кто вступает с нами в общение. Наше эмоциональное состояние отображается и на речевом партнёре, вызывает у него ответную реакцию. Таким образом, результат общения может полностью зависеть от того, как мы обратились к собеседнику, какое вербальное обращение выбрали, какой эмотивный смысл в него вложили.

Как правило, иностранных студентов учат умениям правильно и вежливо обращаться к другому человеку на занятиях по речевому этикету или при изучении темы „Знакомство”. Однако при этом часто ограничиваются всего лишь этикетными формулами, не акцентируя внимания на какие-либо нюансы в употреблении их отдельных составляющих, не указываются различные эмотивные смыслы конкретных лексических единиц. Причём, например, Шаховский предлагает разделять эмотивные смыслы на интернациональные, национальные, групповые (детские, личностные, семейные, профессиональные) [Шаховский 2008: 246]. Наша задача - сопоставляя обращения трёх славянских языков, выявить их различия в употреблении, а также национальный или даже интернациональный эмотивный смысл. Как отмечает Светлана Котовская,

первоначально обращения подразделялись лингвистами на узуальные (не зависящие от эмоционального плана и используемые при официальных, формальных отношениях) и окказиональные (осуществляющие эмоциональный план отношений между коммуникантами в обиходной и фамильярной речи) [Котовская 2011: 40-41].

В практике речевого этикета все обращения принято делить на две больших группы: обращения к знакомому и незнакомому человеку [Формановская 2009: 117, 138]. С точки зрения речевого поведения Конкордия Курилова предлагает классифицировать эти речевые единицы на почтительные, нейтральные, ласкательные, уничижительные, насмешливые, шутливые, по прозвищу, псевдониму, изящные, фамильярные, грубые, вульгарные и некие особые [Курилова 1997]. Елена Сухова в свою очередь опирается на следующую классификацию обращений: 1) обращения, используемые для оказания уважения адресату; 2) обращения, используемые для выражения нежных чувств к адресату; 3) обращения, используемые для выражения любовных чувств к адресату; 4) обращения, употреблённые в переносном значении; 5) обращения- 
-ругательства, обращения-оскорбления, грубые обращения-ругательства [Сухова 2001].

Татьяна Жукова делит обращения по признаку положения коммуникантов во времени и пространстве на контактные и дистантные, в зависимости от признака номинации - по признакам родства, по половозрастным отличиям, по социальному статусу и роли. Кроме обращений-номинативов (или индексов), вслед за Валентином Гольдиным, учёная различает обращения-регулятивы (или отношения), „главная функция которых - выражение относительного положения адресанта и адресата, распределение ролей и регулирование отношений между общающимися" [Гольдин 1978: 80]. Владимир Ильич Карасик предлагает классифицировать обращения на стандартные - определённые и неопределённые - и нестандартные. К стандартным определённым обращениям он зачисляет статусные, дейктические, антропонимические и эмотивные, а к нестандартным - любые слова, которые могут выступать в роли обращений [Карасик 2002: 210; Жукова 2015: 56-59]. Как видно, лингвисты выделяют эмотивные обращения среди других групп обращений, а некоторые даже определяют их в самостоятельную категорию и, кроме того, разграничивают в соответствии с чувственным восприятием человека.

В рамках нашей работы мы будем рассматривать обращения, выполняющие прагматическую и экспрессивную функции, иными словами те, что отображают эмоции (мы их условно назовём эмотивы), и те, с помощью которых мы воздействуем на собеседника, влияем на его чувства (регулятивы). Придерживаясь традиционной классификации, то есть описывая обращения к знакомому и незнакомому человеку, мы попытаемся выделить обращения, вызывающие у собеседников положительные или отрицательные эмоции. Для этого мы обратимся к когнитивно-прагматическому подходу, в основу которого легло изучение ассоциативного языкового сознания носителей различных культур и выделение их основных концептов. К положительным эмоциям мы, вслед за Кэрролом Эллисом Изардом, условно отнесём радость, интерес и удивление, к отрицательным - печаль, гнев, отвращение, презрение и страх [Изард 2007: 26, 49].

Обычно при обращении к незнакомому человеку мы учитываем его возраст, пол, социальное положение (можно определить по одежде и другим внешним атрибутам), переменную роль (пассажир, прохожий и под.) и, безусловно, ситуацию общения. Часто, привлекая к себе внимание, в славянском речевом этикете принято избегать конкретной формы обращения, используя такие формулы, как Простите! ИзВините! Будьте добры (любезны)! - в русском языке; Прабачце! Скажыце! Будзьце такі 
^аскавы! - в белорусском языке; Prepáčte! Smiem spýtat? Prosím! - в словацком языке и т.д.

Однако следует помнить, что „обращение к незнакомому, как правило, характеризует не личностное, а ролевое общение" [Формановская 2009: 126].

При этом способе коммуникации мы часто играем, скрываем эмоции перед собеседником (хотим быть вежливыми), либо, наоборот, их проявляем („выпускаем накопившийся пар”), поскольку с такими людьми мы не связаны эмоционально. Это необходимое общение со стороны адресанта можно назвать вынужденным, а со стороны адресата - добровольным. В ситуации при обращении к незнакомому человеку эмоциональным, скорее всего, будет ответ, чем само обращение (таким образом, проявляется наше настроение в желании или нежелании общаться).

Однако за пределами деловой коммуникации мы очень часто встречаем стремление вступающего в контакт создать непринуждённую, дружескую и даже фамильярную обстановку, склонить на свою сторону собеседника, сразу урегулировать отношения. В данном случае речь пойдёт об обращениях-регулятивах. При обращении к близкому, знакомому или малознакомому человеку мы вольно или невольно выражаем своё отношение к нему и часто проявляем чувства и эмоции. И от степени знакомства эмоции будут проявляться менее или более ярко. Таким образом, согласно нашим предположениям, к знакомым людям мы обращаемся, используя, чаще всего, эмотивы или эмотивы-регулятивы. Возможно, данное разделение обращений является слишком примитивным и упрощённым и, безусловно, требует ещё дальнейшего глубокого изучения, однако в данной ситуации, кажется нам, вполне адекватным и приемлемым в учебной практике.

Итак, обратим внимание на примеры. Сейчас мы рассмотрим только один синонимический ряд слов, отдельные лексемы которого могут встречаться в различных группах обращений - к знакомому и незнакомому человеку. В практике преподавания иностранного языка принято изучать, как правило, наиболее часто употребляющиеся в этой роли слова.

Обратимся к слову-обращению бабушка. Оно обычно используется для наименования мамы отца или матери, но иногда его можно услышать и при обращении к любой старой женщине:

- Бабушка, - Тима подошёл и присел на кровать, - я тебя никогда не брошу (Маша Трауб);

- Русская земля большая, бабушка. Место для нас найдётся (Алексей Пантелеев);

- Бабушка, бабушка, почему Бим на трёх ногах? (Гавриил Троепольский);

- Бабушка, почему у нас ёлка? Ведь сейчас лето (Светлана Алексиевич) ${ }^{1}$ и т. п.

1 Здесь и далее в работе представлены примеры, взятые из основного и параллельного (белорусского) национального корпуса русского языка [см. НКРЯ]; а также из словацкого национального корпуса [см. SNK]. 
В современном русском языке среди синонимичных слов бабуля (бабулька), бабуся, баба наиболее продуктивным с точки зрения употребления является бабушка. Оно воспринимается носителями русской речи как нейтральное, хоть в своём морфемном составе имеет экспрессивный суффикс -ушк-. Во втором случае (при обращении к старой женщине) эта лексема носит уже разговорный характер. В практику преподавания иностранного языка следует, как нам кажется, вводить в речь студентов и экспрессивные наименования к слову бабушка. На их эмоциональность (обучающие сами должны это определить) указывают специфические аффиксы: суффиксы -ул' (-ульк-), -ус'-.

В белорусском языке вышеприведённому ряду слов будут соответствовать лексемы бабуля (бабулька), бабка, бабуся и баба. Русскому слову бабушка здесь соответствует наименование бабуля:

- Галубка Наталка... мядку хочаш? - Але, бабуля! Хачу! - звонка закрычала Наталяя Пятроунна, смеючыся (Іван Шамякін);

Трубку ӱзяа жонка. - Слухай, бабуля... Мэблю купіла? (Іван Шамякін).

А для обращения к любой старой женщине чаще практикуется слово бабка:

Кончык бабчынага кійка дробненька дрыжыць на асфальце. - Не бойся, бабка. Гэта - саюют (Васіль Быкаӱ);

- А, гэта ты, бабка! Ну, прысядзъ, пагаворым трохі (Якуб Колас).

Нужно сказать, что в русском языке в таком случае чаще используется лексема бабуля:

Продавщиица взглянула на неё, широко раскрыв глаза:

- Вымне ничего не давали, бабуля. Я не дура вам какая-нибудь! (Александр Маслов);

- Так вот, бабуля, у нас на подстанции всего две кардиобригады (Влада Валеева).

Как видно из примеров, слова-обращения бабуля, бабка, бабушка указывают на доброжелательное отношение к собеседнику.

В словацком языке вышеприведённым словам соответствуют наименования stará mama (matka, mat'), starká, babka, babička, babenka, babinka, baba. В качестве обращения здесь чаще употребляются первых два слова, причём starká является разговорным синонимом к starej matke:

No, stará matka, tu som! Porad'te, čo d'alej! (Pavel Dobšinský);

Bol už večer, dievčence usilovne priadli, a mladý pán vel'mi začudoval, ked'videl Hanku driemat' pri peci. I vravi matke: Stará mat', povedzte mi, prečo tamtá nepradie? (Pavel Dobšinský);

Chod'te von, starká, zavolal na ňu hnevno (Svetozar HurbanVajanský). 
Согласно примерам, в словацком языке слова stará mama и starká используются при обращении как к родной бабушке, так и просто к малознакомой старой женщине. Кроме того, лексема starká в словацкой разговорной речи может употребляться при обращении мужа к жене: Tak už vieš, starká, čo sa stalo? (Martin Rázus). Остальные вышеуказанные лексемы носят не только номинативный, но и экспрессивно-эмоциональный характер, о чём также свидетельствует их морфемная структура - суффиксы -к-, -ičk-, -enk- (-ink-).

Как видно из примеров, для обращения к старой женщине в трёх языках используется слово баба. Однако не равнозначны случаи его употребления:

- Ну что ж вы, баба Нюра, всё так близко к сердиу принимаете, никакого валокордина не хватит (Дмитрий Бавильский);

- Баба Мария, меня зовут Настя, как можно вежливее говорит девушка, обуздывая раздражение (Татьяна Соломатина);

- Баба, з пенкаю малачка нарабі! 3 пенкаю! - гаворыць ён. Баба Ганна нацырыла адну конаујку, падала Колю (Павел Місько).

Так, для русского и белорусского языков лексема баба является разговорным вариантом для слов бабушка/бабуля/бабка, причём оно может иметь и грубоватый оттенок, однако, как правило, не в значении обращения к родной бабушке, а в значении 'женщина, жена':

- Нет, баба, хитрей вашего бабъего рода на этом свете и твари нет! (Антон Чехов);

Сквозь туман в глазах она видела перед собой офицерика, лицо у него было красное, натужное, и он кричал ей:

- Прочь, баба! (Максим Горький);

- Баба, - загадау Алесь адной з катаржанак, - перацягні яму рану (Уладзімір Караткевіч);

- Собственно, жонка завязе, калі б кабыла уицякла. (Да Агаты.) Праууда, баба? (Янка Купала);

- Зарэж, дзед, бычка!

- Ці не здурнела ты, баба? - здзівіутся дзед. - Навошта нам яго рэзаць? (Народная казка

Залатая яблынька).

Слово баба как обращение к родной бабушке часто используется в детской речи русских, белорусов и словаков. В русском языке лексема баба в роли обращения может употребляться при именовании знакомой старой женщины (обязательно с указанием её имени) и вообще женщины, в белорусском - при обращении к жене и любой женщине. В словацком языке, являясь обращением в значении 'бабушка', слово baba также имеет оттенок разговорности, однако в современном языке встречается преимущественно как диалектное. Зато часто мы его слышим в разго- 
ворной речи (в форме множественного числа) в роли фамильярного обращения к женщинам - baby. Таким образом, обращение баба при именовании женщины или жены мы также считаем эмотивным.

Что касается лексемы бабуся, то, на наш взгляд, употребление его в русском и белорусском языках имеет свои особенности. Так, в русском языке это слово содержит фамильярный, даже иронически снисходительный оттенок, употребляется как обращение к незнакомой или малознакомой старой женщине:

- Кто ж нынче не может плакать, а? Бабуся, вы умеете плакать? - спросила она П.П., и вредная старушонка ответила... (Игорь Адамацкий);

Старушка плакала.

- Что это вы, бабуся? - спросил я (Самуил Алешин);

- А что на этот раз стряслось, бабуся? (Сергей Романов).

В белорусском языке - слово бабуся, скорее, является синонимичным к обращению бабка, имеет ласкательное, хоть, как и в русском языке, фамильярное значение:

Цяпер я толькі нядбайна супакойваю: Нічога, нічога, бабуся... Мы пераходзім вуліиу (Васіль Быкау);

І хоць Лемяшэвіч не надта быу ласы да мёду, але весела крыкнуў:

- Хачу, бабуся! Вельмі хачу! (Іван Шамякін).

При ознакомлении студентов-иностранцев с данными синонимическими рядами следует обратить внимание обучающихся и на то, что лексемы babul'a/babul'ka - русско-белорусско-словацкие межъязыковые омонимы. Эти словацкие слова являются многозначными и также достаточно часто используются как обращения к девушке или молодой женщине, только имеют более нежный оттенок. Кроме этого, ими так ласково называют домашнюю птицу - гусей:

Len sa upokoj babul'ka;

Len sa upokoj babul'ka (Anton Habovštiak);

Ako si spala, babul'ka, babulienka?;

Ale, babul'ka, ktože ti to povedal?;

Hus tak na jar vyvedie kŕdlik zlatožltých babuliat (Anton Habovštiak).

Ещё в словацком языке часто употребляется лексема bobul'a (bobul'ka), которая могла бы стать обращением в похожих ситуациях, так как в русском и белорусском языках ей соответствует слово ягода (ягодка), служащее довольно часто в качестве ласкового просторечного (фамильярного) обращения к хорошенькой девушке или привлекательной молодой женщине: 
- Не плачь, моя ягодка, не дам я тебя в обиду (Ирина Грекова);

- Марыначка! Ягадка мая! Цвіці на зайздрасиь нам, старым (Іван Шамякін);

- A ты - пупсик, ягода, котик и солнышко, - отвечал я Карине (Иржи Грошек).

Кроме того, для проявления доверительного отношения к собеседнику в разговорной речи словаков довольно часто употребляется обращение тоја. Его можно услышать в коммуникации с близкими и даже малознакомыми людьми при обращении к женщине или девушке:

Si doma, moja?;

No, milé moje, ja som začala s redukčnou diétou;

Už si vel'mi unavená, Dominika? Nevládzeš, moja? (Ladislav Ťažký);

Zakývaj, moja, ujovi rušňovodičovi, - povedala matka mladšej dcérke.

Предполагаем, что такие языковые параллели при обучении студентов-иностранцев на занятиях по практике речи будут полезны, так как сопоставление родного и изучаемых языков и объяснение нюансов употребления различных синонимичных форм только поспособствует более глубокому их усвоению.

Таблица 1.

\begin{tabular}{|l|l|l|}
\hline \multicolumn{1}{|c|}{ Русский язык } & \multicolumn{1}{|c|}{ Белорусский язык } & \multicolumn{1}{c|}{ Словацкий язык } \\
\hline Бабушка (нейтр.) & $\begin{array}{l}\text { Бабуля (нейтр.) / бабка } \\
\text { (разг.) }\end{array}$ & $\begin{array}{l}\text { Stará matka (mama, mat') - } \\
\text { нейтр., starká - разг. }\end{array}$ \\
\hline Баба (разг.) & Баба (разг.) & Baba (диал.) \\
\hline $\begin{array}{l}\text { Бабуля / бабулька (разг.); } \\
\text { бабуся (разг., фам. ирон.) }\end{array}$ & $\begin{array}{l}\text { Бабулька, бабуся (разг., } \\
\text { фам. ласк.) }\end{array}$ & $\begin{array}{l}\text { Babka, babička, babinka, } \\
\text { babenka (разг.); } \\
\text { moja (разг. фам.) }\end{array}$ \\
\hline
\end{tabular}

При работе с обращением бабушка у большинства студентов (это, конечно, зависит от личного опыта каждого) возникнут преимущественно положительные эмоции. Эту же мысль, как нам кажется, подтверждает Славянский ассоциативный словарь (2004), в котором к слову-стимулу бабушка [САС 2004: 24, 25] приводятся ассоциации из русского, белорусского, болгарского и украинского языков. Эти данные были получены на основе свободного ассоциативного эксперимента. Его результат - образы сознания, „интегрирующие в себе умственные и чувственные знания, которыми обладает конкретный этнос" [Щенникова 2016: 67]. Обобщая накопленный опыт работы по когнитивной и социальной лингвистике, следует подчеркнуть значение таких словарей для дальнейшего исследования полученных данных: 
...ассоциативный тезаурус является отражением ментально-эмоционального состояния среднего носителя языка, не конструируется, а выводится, извлекается из памяти носителя языка и фиксируется составителями с исследовательскими целями [Щенникова 2016: 66-67].

Таким образом, при более внимательном анализе словарных статей мы обнаружили, что в русском языке лексема бабушка вызывает у респондентов в равной степени как положительные, так и отрицательные эмоции, несмотря на то, что в самом слове закрепилось устойчивое эмоционально-экспрессивное, ласкательное значение. В белорусском языке преобладают положительные эмоции, хоть также сознание носителей языка реагирует на данное слово с различными негативными чувствами. Так, из представленных слов-ассоциаций в русском языке 28 имеют позитивную оценку (на это указывают лексемы добрая, любимая, родная, ласковая; тепло, мудрость, нежность, друг и т.д.), 14 - негативную (злая, ворчливая, замучила, неприятность, скука, сплетница и т.п.). В белорусском - 16 лексем с негативной семантикой (крык, жаль, маразм, скнара, дрэнная и т.д.), 50 - с позитивной (цяпло, пящчота, шчырая, найлепшая, павага, усмешка, другая матуля, родная жанчына и под.). К сожалению, ещё не создан ассоциативный словарь словацкого языка, поэтому мы только предполагаем, что, скорее всего, похожая картина возможна и в словацком языке, тем более что в болгарском и украинском положительный эмотивный смысл в словах баба (болг.) и бабуся (укр.) явно преобладает.

Как видно из примеров, взятых преимущественно из основного русского и параллельного белорусского, а также словацкого народного корпусов, в качестве обращения слово бабушка может быть использовано по отношению как к хорошо знакомому, родному человеку, так и к малознакомому или незнакомому вообще. Согласно нашим рассуждениям, оно может выступать как эмотивное обращение и обращение эмотивно-регулятивное, отражающее языковым сознанием положительные и отрицательные эмоции. Причём позитивный оттенок значения более ярко проявляется в белорусском языке, что, пожалуй, даёт основания говорить о положительном национальном и даже, возможно, интернациональном эмотивном смысле этого слова-обращения.

\section{Библиография}

Богданова Г. А. 1995. Речевой этикет: обучаем речевому этикету, Москва: Просвещение.

Гольдин В. Е. 1978. Этикет и речъ, Саратов: Издательство Саратовского университета. Гольдин В. Е. 2009. Обращение. Теоретические проблемы, Москва: Либроком. 
Гущина Л. В. 2006. Фатическая фрнкиция обращения в диалогической речи (на материале современного английского языка). Диссертация на соискание ученой степени кандидата филологических наук, Ростов-на-Дону: РГПУ.

Доуггаль А. 2008. Сродкі выражэння эмоцый у сучаснай беларускай мове, Мінск: Тэхналогія.

Жукова Т. С. 2015. Обращения в регламентированных сфрерах общения: становление новой нормы. Диссертация на соискание ученой степени кандидата филологических наук, Москва: РГГУ.

Изард Э. К. 2007. Психология эмоиции, Санкт-Петербург: Питер.

Карасик В. И. 2002. Язык социального статуса, Москва: ИТДГК Гнозис.

Кожухова Л. В. 2007. Речевой акт обращения, „Вестник Ставропольского государственного университета", № 48.

Котовская С. С. 2011. Прагматика обращения в риторическом вопросе, [в:] С. С. Котовская (ред.), Концепты и перспективы немецкого языкознания и митературоведения в межкультурном дискурсе, Минск: БГУ.

Курилова К. А. 1997. Обращения В современном китайском языке. Диссертация на соискание ученой степени кандидата филологических наук, Владивосток: ВГУ.

Орлова Н. Н. 2009. Языковые средства выражения эмоиий: синтаксический аспект: на материале английской прозы. Диссертация на соискание ученой степени кандидата филологических наук, электронный ресурс: http:/ / www.dissercat.com/content/ yazykovye-sredstva-vyrazheniya-emotsii-sintaksicheskii-aspekt-na-materialesovremennoi-angli\#ixzz4o3SJA7LN (доступ 15.08.2017).

Савчук Т. Н. 1996. Речевой этикет в русских и белорусских народных сказках. Автореферат диссертации на соискание ученой степени кандидата филологических наук, Минск: БГУ.

Солахаў А. В. 2016. Навучанне маўленчаму этыкету: даведачныя матэрыялы, Мазыр: МДПУ імя І.П. Шамякіна.

Стернин И. А. 1996. Русский речевой этикет, Воронеж: ВОИПКиПРО.

Сухова Е. Ф. 2001. Лингвокультурологический анализ русского речевого этикета (обращение) на фоне арабской речевой культуры. Диссертация на соискание ученой степени кандидата филологических наук, Москва, электронный ресурс: http:/ / www. dissercat.com/content/lingvokulturologicheskii-analiz-russkogo-rechevogo-etiketaobrashchenie-na-fone-arabskoi-rec (доступ 05.07.2017).

Формановская Н. И. 2009. Речевой этикет в русском общении. Теория и практика. Москва: ВК.

Шаховский В. И. 2008. Лингвистическая теория эмоций, Волгоград: ВГПУ Перемена.

Щенникова Н. В. 2016. Влияние рекламных текстов на языковое сознание современного подростка (13-15 лет): психолингвистический аспект. Диссертация на соискание ученой степени кандидата филологических наук, Москва: РУДН.

Dolník J. 2000. Učitel'a jazyková kultúra, Banská Bystrica: Metodické centrum.

Findra J. 2013. Jazyková komunikácia a kultúra vyjadrovania, Martin: Osveta.

Lomenčík J. 2010. Jazyková kultúra vo výučbe slovenského jazyka (parciálne pohl'ady), [в:] J. Kačala, I. Sedlák (сост.), Zborník Matice slovenskej. Jazykoveda, roč. 1, Martin: Národný inštitút slovenského jazyka a literatúry Matice slovenskej vo vydavatel'stve MS.

Škvareninová O. 2004. Rečovvá komunikácia, Bratislava: Mlladé letás. 
Список сокращений

НКРЯ. Национальный корпус русского языка, электронный ресурс: http:// ruscorpora.ru/search-main.html

САС 2004. Уфимцева Н.В., Черкасова Г.А., Караулов Ю.Н., Тарасов Е.Ф. Славянский ассоииативный словарь: русский, белорусский, болгарский, украинский. Москва: Издательство.

SNK. Slovenský národný korpus, электронный pecypc: http:/ / slovniky.korpus.sk 
